\title{
Maturação nuclear in vitro de ovócitos bovinos selecionados pelo método azul cresil brilhante
}

\author{
In vitro nuclear maturation of bovine oocytes selected by the brilliant cresyl \\ blue method
}

\section{Maduración nuclear in vitro de ovocitos bovinos seleccionados por el método azul cresil brillante}

\author{
Otero A Rafael ${ }^{1 *}$ Ph.D, Da Costa P Eduardo²Ph.D, Pereira M Emílio ${ }^{3}$ Ph.D. \\ ${ }^{1}$ Universidade de Sucre. Facultad de Ciencias Agropecuarias, Departamento de Zootecnia. \\ Grupo de Investigación Mejoramiento y Reproducción Animal Sincelejo, Colombia. \\ 2Universidade Federal de Viçosa, Departamento de Medicina Veterinária, Viçosa, Minas Gerais, Brazil. \\ ${ }^{3}$ Universidade Federal de Uberlândia, Departamento de Medicina Veterinária, Uberlândia, Minas Gerais, Brazil.
}

\section{Keywords:}

Ovocytes;

Brilliant Cresyl Blue; In vitro maturation.
Palavras-chave:

Ovócitos;

Azul cresil brilhante; Maturação in vitro.
INFORMACIÓN

Recibido: 21-05-2017;

Aceptado: 09-10-2017.

Correspondencia autor:

rafael.otero@unisucre.edu.co

\section{Abstract}

The objective was to investigate in vitro nuclear maturation of bovine oocytes selected by Brilliant Cresyl Blue (BCB) after maintenance in Talp-Hepes medium. Cumulus oocyte complexes (COCs) obtained from slaughterhouse ovaries were randomly assigned to 6 treatments. I. As a percentage of oocytes that presented nuclear configuration of MI (Metaphysis I) at the end of IVM, T3 and T5 were higher than T1, T2 and T4 ( $p<0.05)$. As for the ability of oocytes to complete IVM, expressed by competence in reaching MII (Metaphysis II), T1, T2, and T4 treatments presented a higher percentage of MII than T3 and T5 $(p<0.05)$. Of the oocytes submitted to IVM, T1 had a lower percentage of degenerates than T2, T3, T4, T5 $(p<0.05)$. It was concluded that the ability of staining of oocytes by BCB did not change after maintenance of CCOs for 5 hours in Talp-Hepes and that BCB dye showed to be effective in the selection of more competent oocytes after maintenance of CCOs for $5 \mathrm{~h}$ in Talp-Hepes.

\section{Resumo}

Objetivou-se investigar a competência in vitro da maturação nuclear de ovócitos selecionados pela técnica do corante Azul Cresil Brilhante (ACB), após manutenção em meio Talp-Hepes. Complexos cumulus ovócito (CCOs) foram obtidos de ovários de matadouro e distribuídos aleatoriamente em 6 tratamentos. Quanto percentual de ovócitos que apresentaram configuração nuclear de MI (Metáfise I) ao término da MIV, notou-se que T3 e T5 apresentaram-se superiores ao T1, T2 e T4 $(p<0,05)$. Quanto à capacidade dos ovócitos de completarem a MIV, expresso pela competência em atingirem MII (Metáfise II), observou-se que os tratamentos T1, T2, T4 apresentaram maior percentual em MII que T3 e T5 $(p<0,05)$. Dos ovócitos submetidos a MIV, T1 apresentou menor percentual de degenerados que T2, T3, T4, T5 $(p<0,05)$. Concluiu-se que a capacidade de coloração de ovócitos por ACB não alterou após manutenção dos CCOs por 5 horas em Talp-Hepes e que o corante ACB mostrou-se eficaz na seleção de ovócitos mais competentes após manutenção de CCOs por $5 \mathrm{~h}$ em Talp-Hepes. 


\section{Introdução}

Na produção in vitro de embriões (PIVE), o advento da aspiração folicular guiada por ultrassom (OPU-Ovum Pick Up) possibilitou a obtenção de complexos cumulus ovócitos (CCOs) a partir de doadoras vivas (MAPLETOFT e HASLER 2005; DENIS, 2008), fato este que impulsionou definitivamente a PIVE. Entretanto, situações como o transporte dos CCOs do local de coleta até o laboratório, assim como métodos adequados que avaliem a competência desses COCs, ainda permanecem como desafios e necessitam ser profundamente compreendidos (BLONDIN, 2017).

Meios de manutenção/transporte de COCs utilizados, assim como o $\mathrm{pH}$ e a temperatura destes influenciam os resultados de produção de embriões (TWAGIRAMUNGU et al., 1998; SCHWARTZ et al., 1998; LEIVAS et al., 2004; KONRAD et al., 2013). Outro fator demonstrado interferir negativamente na PIV é a baixa qualidade dos ovócitos selecionados para a maturação in vitro (MIV) (MACHATKOVA et al 2004; DESSIE et al. 2007). Tal fato compromete a fertilização ou limita o desenvolvimento embrionário, principalmente durante as primeiras clivagens até a ativação do genoma embrionário (GANDOLFI e GANDOLFI, 2001).

Aspectos morfológicos de seleção de ovócitos são utilizados rotineiramente em laboratórios, na qual o número de camadas de células do cumulus, grau de compactação destas (MADISON et al., 1992), e o aspecto do citoplasma (HAWK e WALL, 1994) são parâmetros adotados na avaliação. No entanto, o baixo percentual de ovócitos que atingem o estádio de blastocisto in vitro, demonstra que tal seleção visual é subjetiva, não demonstrando a real competência dos CCOs utilizados (DE LOOS et al., 1992; DESSIE et al. 2007). Não obstante, as técnicas de seleção dos gametas competentes devem cumprir alguns prérequisitos: serem simples e rápidas, de baixo custo e alta confiabilidade e, acima de tudo, não serem tóxicas para os ovócitos e as células somáticas que o circundam (GOOVAERTS et al., 2010; BOLS et al., 2012, CONZATTI, 2013).

Neste contexto, o corante Azul Cresil Brilhante (ACB) tem sido empregado amplamente como método de seleção morfológica de CCOs, na tentativa de otimizar a seleção de ovócitos imaturos mais competentes para a PIVE, sendo descrito sua utilização com sucesso em várias espécies (RODRÍGUEZ-GONZÁLEZ, et al., 2002, 2003; PUJOL, et al., 2004; ALM et al.,2005; WONGSRIKEAO et al., 2006; KĄTSKAKSIAZZZKIEWICZ et al., 2007; MANJUNATHA et al., 2007; RODRIGUEZ et al., 2009; MOTA et al., 2010; PEREIRA et al., 2013; TABANDEH et al., 2012; CASTANEDA et al., 2013; SU et al., 2012; MIRSHAMSI et al., 2013; BUDNA et al. 2017).

Ao longo da oogênese, RNAs e proteínas se acumulam no interior do ovócito (FAIR et. al. 1995), como a Glicose- 6 fosfato desidrogenase (G6PDH) (CETICA et al., 2002). A G6PDH participa da via das pentoses fosfato no metabolismo de glicose, fornecendo NADPH (um redutor intracelular) e Ribose (substrato para a síntese de ácidos nucléicos) importantes para o crescimento celular (TIAN et al 1998). A enzima G6PDH apresenta maior atividade em ovócitos em crescimento quando comparada aqueles ovócitos que atingiram seu crescimento final (MANGIA e EPSTEIN, 1975). Dada à capacidade da enzima G6PDH degradar o corante ACB e o padrão metabólico descrito, tem sido possível selecionar ovócitos imaturos bovinos mais competentes, de citoplasma azul $(\mathrm{ACB}+)$, daqueles, menos competentes de citoplasma incolor (ACB-) (PUJOL et al., 2004; ALM et al., 2005; OPIELA et al., 2008; MOTA et al., 2010). Ovócitos ACB+ tem demonstrado maior diâmetro (ALM et al., 2005; PUJOL et al., 2004), maior volume, maior número de cópias de DNAmt (DNA mitocondrial) (EL SHOURBAGY et al., 2006) e maiores taxas de maturação nuclear in vitro (ALM et al., 2005; MANJUNATHA et al., 2007; PRAXEDES et al, 2014) que ovócitos ACB-.

Devido tais circunstâncias, o corante ACB poderia ser utilizado como uma ferramenta de auxílio à seleção de COCs depois de prolongado período de manutenção/transporte. Desta forma, tornaria possível distinguir com maior precisão aqueles ovócitos mais competentes para os sistemas de produção in vitro de embriões. O objetivo do trabalho foi de avaliar a competência de maturação nuclear in vitro de COCs bovinos imaturos selecionados por ACB, após $5 \mathrm{~h}$ de manutenção destes em meio Talp-Hepes. 


\section{Material e métodos}

Coleta e seleção dos ovócitos. Ovários de fêmeas mestiças (Bos Taurus x Bos Indicus) foram coletados em frigorífico imediatamente após abate dos animais. Após coleta os ovócitos foram transportados em garrafas térmicas em solução fisiológica ( $\mathrm{NaCl} 0,9 \%$ ) acrescida de sulfato de estreptomicina $(100 \mathrm{mg} / \mathrm{L})$, em temperatura variando de 35 a $38^{\circ} \mathrm{C}$ em um período máximo de duas horas.

No laboratório, os folículos ovarianos de 2 a 8 $\mathrm{mm}$ de diâmetro foram puncionados a partir de seringas de cinco mililitros acopladas de agulha 30 x 8 (21G) e o líquido folicular contendo os ovócitos foi depositado em cálices cônicos mantidos dentro do banho-maria à $37^{\circ} \mathrm{C}$. Após o período de decantação de cinco minutos, o pellet contendo ovócitos foi recuperado e transferido para uma placa de Petri.

Os ovócitos recuperados foram selecionados com auxílio de um microscópico estereoscópico (aumento 40x) e classificados morfologicamente, de acordo com COSTA et al. (1997a). Apenas os ovócitos imaturos classificados como cumulus compacto e com até três camadas de células do cumulus foram selecionados para o experimento.

Coloração por ACB. Os CCOs submetidos à coloração foram expostos por 60 minutos a solução de $26 \mu \mathrm{m}$ de ACB (B-5388, Sigma, USA) diluídos em meio Talp Hepes. A exposição dos CCOs a solução de ACB foi realizada em placas Nunc $^{\circledR}$ (Nunc A/S; Cat.176740) sobre placa aquecedora à $37^{\circ} \mathrm{C}$. Ao término do período de exposição os CCOs foram lavados duas vezes em meio Talp Hepes e posteriormente divididos em dois grupos de acordo com a coloração do citoplasma dos ovócitos. Ovócitos apresentando citoplasma azul foram classificados como ACB+ e aqueles demonstrando citoplasma incolor foram classificados como ACB-.

Maturação in vitro dos ovócitos. O meio de maturação in vitro dos ovócitos foi constituído por TCM 199 acrescido de 10\% de SVE (soro de vaca em estro) e $10 \mu \mathrm{g} / \mathrm{mL}$ de FSH (Hormônio Folículo Estimulante). A maturação foi realizada em placas Nunc $\circledast$ de quatro poços, contendo aproximadamente 20 ovócitos em $400 \mu \mathrm{L}$ de meio de maturação em cada poço, em temperatura de $38,5^{\circ} \mathrm{C}$, com $5 \%$ de $\mathrm{CO}_{2}, 95 \%$ de ar atmosférico e $95 \%$ de umidade em estufa incubadora. Os ovócitos foram cultivados nestas condições de temperatura e atmosfera durante 24 horas. Após este período foram submetidos à avaliação da taxa de maturação nuclear.

Delineamento experimental. Um total de 515 ovócitos imaturos foi distribuído em seis tratamentos. No T1 (testemunha) após a decantação e seleção, os ovócitos foram imediatamente submetidos ao procedimento de maturação in vitro, conforme descrito anteriormente. O restante dos ovócitos foram mantidos em Talp-Hepes sobre placa aquecedora a $37^{\circ} \mathrm{em}$ condições atmosféricas do ambiente, por dois tempos diferentes, zero e cinco horas. Ao termino do período de manutenção, os COCs foram submetidos a coloração por ACB por um período de 60 minutos. No tempo zero hora, os ovócitos foram expostos diretamente ao corante ACB. No tempo cinco horas, após o término do período de exposição, os ovócitos foram expostos durante 60 minutos ao corante ACB. Após o período de coloração organizou-se os seguintes tratamentos: corados zero hora (T2), não corados zero hora (T3), corados cinco horas (T4) e não corados cinco horas (T5). Um outro grupo (T6), os ovócitos foram mantidos em Talp-Hepes por 5 horas e submetidos imediatamente a MIV. Em seguida ovócitos de cada tratamento foram submetidos à maturação in vitro para posterior avaliação da taxa de maturação nuclear. Foram realizadas três repetições para cada tratamento.

Avaliação da miv. Para avaliação da taxa de maturação, os ovócitos de todos os tratamentos foram submetidos ao procedimento de remoção do cumulus oophorus (COSTA et al., 1997b). Posteriormente, foram hipotonizados, fixados em lâmina e corados com orceína a $2 \%$, segundo COSTA et al. (1997c). A leitura das lâminas foi realizada em microscópio óptico, com aumento de 1.000X em imersão, para se avaliar o estádio do ciclo celular meiótico. Os ovócitos foram classificados, de acordo com a configuração dos cromossomos, em metáfase II (MII), metáfase I (MI), cromatina condensada em grumos (CCG) ou sem configuração cromossômica (SCC). Foi considerado como maturado nuclearmente os ovócitos que apresentasse configuração 
cromossômica nuclear em metáfase ll e, estruturas que apresentassem o primeiro corpúsculo polar. As taxas de maturação nuclear foram comparadas em tabelas de contingência e analisadas pelo teste de qui-quadrado a $5 \%$ de probabilidade (SAMPAIO, 2002).

\section{Resultados e Discussão}

Ovócitos considerados corados $(A C B+)$ apresentaram coloração citoplasmática azul, enquanto ovócitos classificados como não corados (ABC-) apresentavam coloração de citoplasma sem a presença de alteração, como demonstrado na Figura 1.

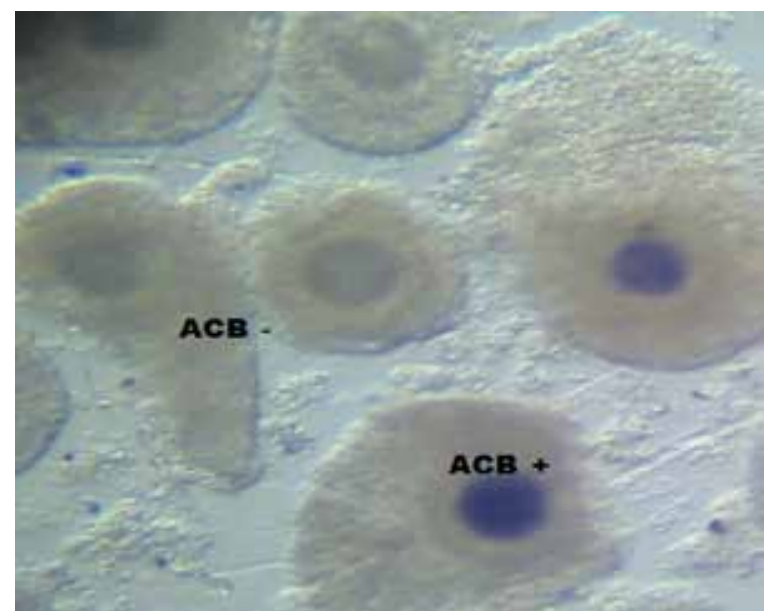

Figura 1. Demonstração dos ovócitos corados (ACB+) e não corados (ACB-) após serem expostos a $60 \mathrm{~min}$ ao corante Azul Crezil Brilhante (ACB). Fonte: Arquivo dos autores

Os resultados referentes às taxas de ovócitos ACB + e ACB-, expostos ao ACB (por 60 minutos) imediatamente após seleção morfológica ou após cinco horas de manutenção em Talp Hepes, encontram-se dispostos na Tabela 1.

Tabela 1 - Taxa de coloração de ovócitos expostos ao corante ACB por 60 min imediatamente após seleção morfológica ou após cinco horas de manutenção em Talp-Hepes

\begin{tabular}{cccc}
\hline $\begin{array}{c}\text { Grupo } \\
\text { experimental }\end{array}$ & $\begin{array}{c}\text { Número de } \\
\text { Ovócitos }\end{array}$ & ACB+ (\%) & ACB- (\%) \\
\hline G1 & 211 & $114(54,0)^{\mathrm{a}}$ & $97(46,0)^{\mathrm{b}}$ \\
G2 & 219 & $129(58,9)^{\mathrm{a}}$ & $90(41,1)^{\mathrm{b}}$ \\
\hline
\end{tabular}

Grupo 1 - Ovócitos expostos ao corante ACB logo após seleção morfológica

Grupo 2 - Ovócitos expostos ao corante ACB após período de cinco horas em Talp-Hepes

Letras iguais na mesma coluna indicam valores semelhantes $(p>0,05)$ pelo teste de qui-quadrado.

No presente trabalho a taxa de ovócitos $\mathrm{ACB}+\mathrm{e}$ ACB- quando expostos a solução de coloração por uma hora, foram semelhantes às taxas encontradas por MANJUNATHA et al. (2007). Estes autores, apesar de trabalharem com ovócitos de búfalas, submeteram os $\mathrm{CCOs}$ a mesma concentração de ACB $(26 \mu \mathrm{M})$ diluído em mPBS e durante o período de $90 \mathrm{~min}$ de exposição, em condições de incubação, encontrando taxas de $57 \%$ de ovócitos $A C B+$ e $43 \%$ de ovócitos classificados como ACB-, valores próximos aos encontrados neste trabalho. Ao testarem o corante em CCOs bovinos, aspirados de ovários de animais abatidos, ALM et al. (2005) e MOTA (2008) encontram taxas de $58 \%$ (ACB+); 42\% (ACB-) e $60 \%(A C B+) ; 40 \%$ (ACB-), respectivamente, valores também similares aos apresentados neste experimento. Adicionalmente, BHOJWANI et al. (2007) buscando utilizar esta técnica para selecionar ovócitos ACB+ imaturos bovinos para a produção de embriões, pela técnica de Transferência Nuclear de Células Somáticas, obtiveram $59,4 \%$ de ovócitos ACB+ e 40,6\% de ovócitos ACB-.

Diferente do presente experimento, os trabalhos até aqui citados expuseram os $\mathrm{CCO}$ s a solução de ACB diluído em mPBS, em estufas incubadoras sob condições de atmosfera umidificada e não sobre placa aquecedora em condições de umidade ambiental. De acordo com as taxas descritas e comparadas neste trabalho, a exposição dos CCOs ao ACB em placas Nunc ${ }^{\circledR}$ sobre placa aquecedora (sem controle de umidade), não comprometeu a interação entre a G6PDH e o corante, visto que, as taxas de coloração foram semelhantes. Outro fator de variação é o tempo de exposição dos ovócitos ao corante. Dentre os estudos encontrados, nota-se que MOTA (2008) manteve os CCOs por apenas 60 min, diferente de MANJUNATHA et al. (2007), BHOJWANI et al. (2007) e ALM et al. (2005) que incubaram por 90 min. No entanto, é possível afirmar que os $60 \mathrm{~min}$ de exposição dos CCOs ao ACB são suficientes para que os ovócitos mais competentes se tornem 
corados de azul, possibilitando a referida seleção bioquímica.

Com relação aos ovócitos mantidos por cinco horas em Talp Hepes, simulando transporte do campo para o laboratório, e em seguida expostos ao corante, não verificou-se diferença $(p>0,05)$ nas taxas de ACB+ e ACB- quando comparadas à coloração imediatamente após seleção morfológica (Tabela 1).

Diante destes achados, sugere-se que o corante ACB foi capaz de selecionar os ovócitos mais competentes $(\mathrm{ACB}+)$ mesmo após longo período (5 horas) em condições de transporte simulado. Provavelmente, os níveis e/ou a atividade da G6PDH dos ovócitos em meio Talp-Hepes não alteraram ao longo das cinco horas, e uma vez que as estruturas estavam continuamente expostas ao corante à enzima foi capaz de degradar o ACB da mesma maneira de quando é exposto imediatamente.

LEIVAS et al. (2004) concluíram que o transporte de ovócitos em meio TCM-HEPES por períodos de até 12 horas a $39^{\circ} \mathrm{C}$ não determinaram decréscimo nas taxas de desenvolvimento embrionário in vitro bem como no número de células de blastocistos eclodidos. De acordo com MONTAGNER et al. (2000) a adição de Hepes aos meios de maturação de ovócitos (TCM-199 modificado) e desenvolvimento embrionário (KSOM modificado) minimiza a variação de $\mathrm{pH}$, diminuem a variabilidade dos resultados e incrementam os índices de blastocistos.

Dessa forma, o período de apenas cinco horas de simulação de transporte, somado as propriedades de manutenção da viabilidade do gameta proporcionadas pelo tampão Hepes, mantiveram os CCOs em condições bem semelhantes aqueles ovócitos imediatamente expostos ao ACB. A partir do exposto, pode-se afirmar que o corante ACB se mostrou eficaz na seleção de ovócitos bovinos imaturos, mesmo quando os mesmos foram submetidos a períodos prolongados de transporte simulado.

WONGSRIKEAO et al., (2006) ao testarem a dupla exposição de CCOs suínos observaram que todos os ovócitos classificados como ACB+ ao início da MIV também exibiram o citoplasma corado após exposição ao corante depois de $44 \mathrm{~h}$ de MIV. Apesar dos autores utilizarem espécie distinta e meio de cultivo suplementado com outros fatores (objetivando a maturação nuclear in vitro), impossibilitando assim a comparação direta com o meio Talp Hepes, o fato dos ovócitos $\mathrm{ACB}+$ continuarem classificados como $\mathrm{ACB}+$ após $44 \mathrm{~h}$ corrobora com os achados do presente experimento, de que, a taxa de ovócitos ACB+ após zero ou cinco horas em Talp Hepes continua semelhante.

Neste trabalho, foi também avaliada a capacidade de maturação in vitro de ovócitos a partir da seleção dos CCOs corados ou não após seleção morfológica ou após cinco horas de manutenção em Talp Hepes. Os resultados encontram-se sumarizados na Tabela 2.

Tabela 2. Maturação nuclear in vitro de ovócitos $A C B+e$ ACB- selecionados após exposição imediata ao corante ou após cinco horas de manutenção em Talp Hepes.

\begin{tabular}{ccccc}
\hline Tratamentos & N & MI (\%) & MII (\%) & $\begin{array}{c}\text { Degenerados } \\
(\%)\end{array}$ \\
\hline T1-Controle & 105 & $16(15,2)^{\mathrm{a}}$ & $82(78,1)^{\mathrm{a}}$ & $7(6,7)^{\mathrm{a}}$ \\
T2- ACB+ & 98 & $5(5,1)^{\mathrm{b}}$ & $72(73,5)^{\mathrm{a}}$ & $21(21,4)^{\mathrm{b}}$ \\
T3- ACB- & 94 & $29(30,9)^{\mathrm{c}}$ & $36(38,2)^{\mathrm{b}}$ & $29(30,9)^{\mathrm{b}}$ \\
T4- ACB+ (5h) & 103 & $10(9,7)^{\mathrm{ab}}$ & $68(66,0)^{\mathrm{a}}$ & $25(24,3)^{\mathrm{b}}$ \\
T5- ACB- (5h) & 81 & $24(29,7)^{\mathrm{c}}$ & $30(37,0)^{\mathrm{b}}$ & $27(33,3)^{\mathrm{b}}$ \\
\hline
\end{tabular}

Valores com letras sobrescritas diferentes na mesma coluna indicam diferenças $(p<0,05)$ pelo teste do qui-quadrado.

Aproximadamente $70-80 \%$ dos CCOs bovinos submetidos aos sistemas de maturação in vitro atuais, atingem o estádio de MII da meiose (ALM et al., 2005; DODE e ADONA et al., 2001). De acordo com os resultados obtidos neste experimento, observa-se que a taxa de maturação nuclear de ovócitos ACB+ foi superior aqueles ACB-, independente do momento em que foram expostos ao corante. Entretanto, os ovócitos do grupo ACB+ (zero ou cinco horas) não apresentaram maior capacidade de maturação quando comparado ao grupo controle. Esses resultados corroboram os achados de ALM et al. (2005), os quais também obtiveram maior percentual de ovócitos ACB+ $(72,5 \%)$ em Mll comparado aos ovócitos ACB- $(58,1 \%)$. Semelhantemente estes autores também não verificaram maior taxa de maturação 
de ovócitos $\mathrm{ACB}+$ quando comparado ao grupo controle. MANJUNATHA et al. (2007) obtiveram maior percentual de maturação in vitro a partir de ovócitos bubalinos ACB+ $(82,6 \%)$ comparado aos classificados como ACB- $(59,2 \%)$. No entanto, ovócitos ACB+ também apresentaram o mesmo percentual de maturação que o grupo controle.

O percentual de maturação nuclear in vitro de CCOs pode variar principalmente em função do diâmetro dos ovócitos (OTOl et al., 1997; YONG et al.,1997; FAIR et al., 1995). CHRISTMANN et al., (1994) sugeriram que ovócitos em crescimento, ainda não possuem capacidade de ativar o complexo fator promotor de mitose (MPF) devido à presença de inibidores no ooplasma do gameta. De fato, ANGUITA et al. (2007) observaram que ovócitos de maior diâmetro apresentaram maior atividade de MPF ao término da MIV. Além disso, FAIR et al. (1995) argumentaram que ovócitos bovinos apresentando diâmetro $<100$ $\mu \mathrm{m}$ ainda não possuem completa capacidade para transcrição e tradução de importantes mRNAs necessários para a sínteses e ativação de proteínas requeridas para o rompimento do envelope nuclear. Segundo esses autores, ovócitos bovinos adquirem completa competência meiótica quando apresentam cerca de $110 \mu \mathrm{m}$.

Trabalhando com ovócitos de novilhas (7-11 meses), PUJOL et al., (2004) verificaram que ovócitos $\mathrm{ACB}+$ (incluindo a zona pelúcida) apresentam maior diâmetro médio $(152,6 \mu \mathrm{m})$ que os ACB- (147,0 um). Maior diâmetro de ovócitos $A C B+$ também já foi confirmado em porcas (ROCA et al. 1998) e cabras pré-puberes (RODRÍGUEZGONZÁLEZ et al., 2002). Considerando que, ovócitos ACB+ apresentam menor atividade da enzima G6PDH (ALM et al., 2005) tornando-se corados ao término da exposição e que apresentam em média maior diâmetro que os aqueles ACB, verifica-se que os ACB+ apresentam maior competência para a retomada da divisão meiótica, fato este confirmado no presente experimento. $\mathrm{O}$ presente estudo identificou que maior número de ovócitos classificados como ACB- apresentaram a configuração nuclear de $\mathrm{Ml}$ ao término das 24 horas de MIV, comparado ao tratamento controle e aos ovócitos $A C B+$. Tal resultado demonstra que ovócitos ACB- apresentam atraso e/ou incapacidade de completarem a divisão meiótica.
EL SHOURBAGY et al. (2006) demonstraram que ovócitos suínos ACB- apresentam menor número de cópias de DNAmt do que os ACB+. Ainda, WU et al., (2007) trabalhando com ovócitos de camundongas, observaram que ao término da MIV, os ovócitos ACB- apresentaram um padrão de distribuição mitocondrial mais difuso no citoplasma e não próximo a placa metafásica como aqueles ACB+. Tais trabalhos demonstram que a incompetência citoplasmática de ovócitos ACB- pode comprometer diretamente a maturação nuclear.

No presente estudo foi possível notar que ovócitos submetidos ao corante ACB, independente da classificação, apresentaram maiores taxas de degeneração ao término da MIV, comparado ao tratamento controle (não exposto ao corante ACB). Segundo ALM et al., (2005) a exposição dos ovócitos ao ACB por 90 min não está associada à alterações na configuração das cromatinas. No trabalho supracitado verificou-se que $12,5 \%$ dos ovócitos apresentaram sinais de degeneração logo após aspiração dos folículos, e ao término dos 90 min em solução de ACB foi encontrado $15,7 \%$ de ovócitos apresentando sinais de degeneração, caracterizados por cromatina picnótica em vários estágios da meiose ou cromatina degenerada e dispersa pelo ovócito. Da mesma forma, ao avaliar os mesmos parâmetros após a MIV, ALM et al.(2005) observaram que $14,6 \%$ de ovócitos expostos ao ACB mostraram-se degenerados e ao passo que apenas $5,7 \%$ se apresentaram degenerados para o grupo controle (MIV logo após seleção morfológica, sem exposição ao corante). Apesar da concentração mínima para coloração de $26 \mu \mathrm{M}$ de ACB estar sendo enfatizada na maioria dos trabalhos, confirmada por MANJUNATHA et al., (2007), e não apresentar efeitos deletérios ao embrião (TIFFIN et al., 1991), KATSKA-KSIAZKIEWICZ et al. (2007) observaram que do pool total de CCOs de cabras expostos ao ACB, 3,6\% do total apresentaram sinais de degeneração no citoplasma.

De acordo com os autores alguns ovócitos poderiam ser mais sensíveis ao ACB apresentando características apoptóticas. Outra razão que poderia justificar elevação das taxas de degeneração é o tempo de exposição a este corante em condições que não sejam totalmente propícias para a maturação do ovócito. A falta 
de nutrientes essenciais para a completa maturação nuclear e citoplasmática dos ovócitos e possivelmente um reinicio da meiose precoce, em razão da retirada da estrutura do ambiente folicular, poderiam representar causas prováveis de degeneração à ovócitos expostos por um tempo prolongado à soluções corantes.

Portanto, a partir do presente estudo esclareceu duas possibilidades bastante pertinentes. Primeiramente, mesmo que outros parâmetros como a competência para o desenvolvimento embrionário e a qualidade dos embriões não tenham sido analisados, verificou-se que a seleção não invasiva de $\mathrm{CCO}$ s via corante $\mathrm{ACB}$, selecionando ovócitos de maior competência meiótica, é possível na ausência de condições atmosféricas controladas. Adicionalmente, a constatação de que os ovócitos ainda apresentam capacidade de coloração através do ACB mesmo após cinco horas em Talp Hepes, abre possibilidades para que a seleção bioquímica de CCOs possa ser empregada, mesmo após longo períodos compreendidos entre aspiração e o início dos procedimentos de cultivo in vitro. Neste sentido, mesmo na ausência de estufas incubadoras, os CCOs poderão ser submetidos a coloração por ACB sobre placa aquecedora ou mesmo serem submetidos ao teste de coloração durante o transporte para o laboratório em período de 5 horas, no intuito de selecionar bioquimicamente as estruturas mais viáveis e possivelmente mais competentes.

Este estudo precursor abre inúmeras possibilidades futuras para comprovação cientifica da eficiência da utilização de uma classificação química para complexos cumulus oophorus que são utilizados no processo de PIVE de embriões bovinos. Tal fato viria de encontro à necessidade extremamente pertinente de utilização de métodos menos subjetivos e mais precisos para classificação dos gametas femininos.

\section{Conclusões}

A capacidade de coloração de ovócitos por ACB não se altera após manutenção dos mesmos por cinco horas em meio Talp-Hepes.

A competência de ovócitos $A C B+$ em atingir o estádio de MIl é maior que ovócitos ACB-, mesmo após cinco horas de manutenção dos CCOs em meio Talp-Hepes.

\section{Agradecimentos}

À CAPES pelo apoio financeiro concedido.

\section{Referências}

ALM, H.; TORNER,H.; LÖHRKE VIERGUTZ, GHONEIM.I.M.; KANITZ, W. 2005. Bovine blastocyst development rate in vitro is influenced by selection of oocytes by brilliant cresyl blue staining before IVM as indicator for glucose-6-phosphate dehydrogenase activity. Theriogenology 63:2194-2205.

ANGUITA, B.; JIMENEZ-MACEDO, A.R.; IZQUIERDO, D.; MOGAS, T.; PARAMIO,M.T. 2007. Effect of oocytes diameter on meiotic competence, embryo development, p34(cdc2) expression and MPF activity in prepubertal goat oocytes. Theriogenology 67:526-536.

BHOJWANI, S.; ALM, H.; TORNER, H.; KANITZ, W.; POEHLAND, R. 2007. Selection of developmentally competent oocytes through brilliant cresyl blue stain enhances blastocyst development rate after bovine nuclear. Theriogenology 67:341-345.

BLONDIN, P. 2017. Logistics of large scale commercial IVF embryo production. Reproduction, Fertility and Development, 29: 32-36

BOLS, P.E.J.; JORSSEN, E.P.A.; GOOVAERTS, I.G.F.; LANGBEEN, A.; LEROY, J.L.M.R. 2012. High throughput non-invasive oocyte quality assessment: the search continues. Animal Reproduction. 9:420-425. 
BUDNA, J.; CHACHUŁA, A.; KAŹMIERCZAK, D.; RYBSKA, M.; CIESIÓŁKA, S.; BRYJA, A.; KRANC, W.; BORYS, S.; ŻOK, A.; BUKOWSKA, D.; ANTOSIK, P.; BRUSKA, M.; BRÜSSOW, K.P.; NOWICKI, M.; ZABEL, M.; KEMPISTY, B. 2017. Morphogenesis-related gene-expression profile in porcine oocytes before and after in vitro maturation. Zygote. 25(3):331-340.

CASTANEDA, C. A. et al. 2013. Lipid content, active mitochondria and brilliant cresyl blue staining in bovine oocytes. Theriogenology, 79 (3): 417-422. ISSN 1879-3231

CETICA, P.; PINTOS, L.; DALVIT, G.; BECONI, M. 2002. Activity of key enzymes involved in glucose and triglyceride catabolism during bovine oocyte maturation in vitro. Reproduction 124: 675-681.

CHRISTMANN, L.; JUNG, T.; MOOR, R.M. 1994. MPF components and meiotic competence in growing pig oocytes. Molecular Reproduction and Development. 38:85-90.

CONZATTI, M. 2013. Utilização do corante azul cresil brilhante como método de seleção de oócitos humanos destinados à maturação in vitro. Salão de Iniciação Científica UFRGS 25:21-25 : UFRGS, Porto Alegre, RS

COSTA, E.P.; VALE FILHO, V.R.; NOGUEIRA, J.C. et al. 1997a. Tipos morfológicos de ovócitos de bovinos. Arq. Bras. Med. Vet. Zoo.49:417-424.

COSTA, E.P.; VALE FILHO, V.R.; NOGUEIRA, J.C. et al. 1997b. Técnicas para desnudamento rápido de ovócitos de bovinos. Arq. Bras. Med. Vet. Zoo. 49:425-432.

COSTA, E.P.; VALE FILHO, V.R.; NOGUEIRA, J.C. et al. 1997c. Técnica para a avaliação do estágio de maturação "in vitro" de ovócitos bovinos. Arq. Bras. Med. Vet. Zootec. 49:433-440.

DE LOOS, F.;VAN MAURIK, P.; VAN BENEDEN, T.; KRUIP T. 1992. Structural aspects of bovine oocyte maturation in vitro. Molecular Reproduction Developmental 31:208-14.

DENIS, R. 2008. Aspiración folicular in vivo (opu) una nueva perspectiva en el campo de las biotecnologías de la reproducción. Ciencia y tecnologia ganadera (cuba). 2 (2):57-70.

DODE, M.A.N.; ADONA, P.R. 2001. Developmental capacity of Bos indicus oocytes after inhibition of meiotic resuption by6-dimethylaminopurine. Animal Reproduction Science 65:171-180.

EL SHOURBAGY, S.H.; SPIKINGS, E.C.; FREITAS, M.; ST JOHN, J.C. 2006. Mitochondria directly influence fertilization outcome in pig. Reproduction 131: 233-45.

FAIR, T.; HYTTEL, P.; GREVE, T. 1995. Bovine oocyte size in relationship to follicular diameter, maturational competence and rna synthesis. Theriogenology 43:209.

GOOVAERTS, I.; LEROY J.L.; JORSSEN, E.P.; BOLS, P.E. 2010. Noninvasive bovine oocyte quality assessment: possibilities of a single oocyte culture. Theriogenology 74(9):1509-1520. ISSN 1879-3231.

GANDOLFI, T.A.L.B.; GANDOLFI, F. 2001. The maternal legacy to the embryo: cytoplasmic components and their effects on early development. Theriogenology 55:1255-76.

HAWK, H.W.; WALL, R.J. 1994. Improved yields of bovine blastocysts from in vitro-produced oocytes. I. Selection of oocytes and zygotes. Theriogenology, 41:1571-1583.

KATSKA-KSIAZKIEWICZ, L.; OPIELA, J.; RYNSKA, B. 2007. Effects of oocyte quality, semen donor and embryo co-culture system on the efficiency of blastocyst production in goats. Theriogenology 68: 736-744. 
KONRAD, J.L.; SCIAN, R.; GARRIDO, M.J.; TAMINELLI, G.; SANSINENA, M. 2013. Producción de embriones de búfalo por fertilización in vitro luego de la maduración de los ovocitos durante el transporte prolongado. Revista Veterinaria, 24(2): 97-101.

LEIVAS, F.G.; BRUM, D.S.; MEZZALIRA, A.; PILLA, L.F.C.; BERNARDI, M.L.; RUBIN, M.I.B.; SILVA, C.A.M. 2004. Transporte de oócitos bovinos em meio de maturação sem controle de atmosfera gasosa. Ciência Rural 34:219-224.

MACHATKOVA, M.; KRAUSOVA, K.; JOKESOVA, E.; TOMANEK, M. 2004. Developmental competence of bovine oocytes: effects of follicle size and the phase of follicular wave on in vitro embryo production. Theriogenology 61:329-35.

MADISON, V.; AVERY, B.; GREVE, T. 1992. Selection of immature bovine oocytes for developmental potential in vitro. Anim. Reprod. Sci. 27:1-11.

MANGIA, F.; EPSTEIN, C.J. 1975. Biochemical studies of growing mouse oocytes: Preparation of oocytes and analysis of glucose-6-phosphate dehydrogenase and lactate dehydrogenase activities. Developmental Biology, 45:211-220.

MANJUNATHA, B. et al. 2007. Selection of developmentally competent buffalo oocytes by brilliant cresyl blue staining before IVM. Theriogenology 68(9):1299-304. ISSN 0093-691X.

MAPLETOFT, R.J.; HASLER, J.F. 2005. Assisted reproductive Technologies in cattle: a review. Revue Scientifique et Technique 24, 393-403.

MIRSHAMSI, S.M. et al. 2013. Combination of oocyte and zygote selection by brilliant cresyl blue (BCB) test enhanced prediction of developmental potential to the blastocyst in cattle. Anim Reprod Sci, 136(4):245-51, ISSN 1873-2232.

MONTAGNER, M.M.; GONÇALVES, P.B.D.; NEVES, J.P.; COSTA, L.F.S.; BORTOLOTTO, E.B.; FARIAS, A.M.; STRANIERI, P. 2000. Hepes na produção de embriões bovinos in vitro. Ciência Rural 30:469-474.

MOTA, G.B. Desenvolvimento e expressão gênica em oócitos bovinos imaturos selecionados por Azul Cresil Brilhante. 2008. Departamento de Zootecnia - Universidade Federal de Viçosa. Viçosa-MG. 47p. Dissertação (Mestrado em Zootecnia, área de concentração em Reprodução Animal).

MOTA, G. et al. 2010. Developmental competence and expression of the MATER and ZAR1 genes in immature bovine oocytes selected by brilliant cresyl blue. Zygote 18(3):209-16. ISSN 1469-8730.

OPIELA. J.; KATSKA-KSIAZKIEWICZ, L.; LIPIŃSKI, D.; SŁOMSKI, R.; BZOWSKA, M.; RYŃSKA, B. 2008. Interactions among activity of glucose-6-phosphate dehydrogenase in immature oocytes, expression of apoptosis-related genes Bcl-2 and Bax, and developmental competence following IVP in cattle. Theriogenology 69(5):546-55.

OTOI, T.; YAMAMOTOL, K.; KOYAMA, N.; TACHIKAWA, S.; SUZUKI, T. 1997. Bovine oocyte diameter in relation to developmental competence. Theriogenology, 48:769-774.

PEREIRA, G. R. et al. 2013. Selection of developmentally competent immature equine oocytes with brilliant cresyl blue stain prior to in vitro maturation with equine growth hormone. Zygote, p. 1-5, Feb. ISSN 1469-8730.

PRAXEDES, E.A.; DE LIMA, J.M.P.; DE OLIVEIRA, L.O.A.; DOS SANTOS, F.A.; PEREIRA, A.F.; BEZERRA, M.B. 2014. Aspiração folicular em ovários bovinos da região semiárida: tempo de transporte $\mathrm{x}$ qualidade oocitária. Acta Veterinaria Brasilica, 8:85-86. 
PUJOL, M.; LOPEZ-BEJAR, M.; PARAMIO, M. 2004. Developmental competence of heifer oocytes selected using the brilliant cresyl blue (BCB) test. Theriogenology 61(4):735-44.

ROCA, J.; MARTINEZ,E.; VAZQUEZ, J.M.; LUCAS,X. 1998. Selection of immature pig oocytes for homologous in vitro penetration assays with the brilliant cresyl blue test. Reproduction Fertility Development 10:479-485.

RODRIGUEZ-GONZALEZ, E. et al. 2002. Selection of prepubertal goat oocytes using the brilliant cresyl blue test. Theriogenology 57(5):1397-409. ISSN 0093-691X.

RODRÍGUEZ-GONZÁLEZ, E. et al. 2003 Developmental competence of prepubertal goat oocytes selected with brilliant cresyl blue and matured with cysteamine supplementation. Reprod Nutr Dev 43 (2):179- 87. ISSN 0926-5287.

RODRIGUES, B. et al. 2009 Preliminary Study in Immature Canine Oocytes Stained with Brilliant Cresyl Blue and Obtained From Bitches with Low and High Progesterone Serum Profiles. Reproduction in Domestic Animals 44 (2):255-258. ISSN 0936-6768.

SAMPAIO, I.B.M. 2002. Estatística aplicada à experimentação animal. Fundação de Ensino e Pesquisa em Medicina Veterinária e Zootecnia. Belo Horizonte, Brasil.

SCHWARTZ, J.; SCHNEIDER, M.R.; RODRIGUES, J.L.; REICHENBACH, H. D. 1998. Effect of short-term storage of bovine oocytes in different media and temperatures on the subsequent in vitro embryo development. Theriogenology 49:217.

SU, J. et al. 2012. Oocytes selected using BCB staining enhance nuclear reprogramming and the in vivo development of SCNT embryos in cattle. PLoS One 7 (4):36181. ISSN 1932-6203.

TABANDEH M.R.; GOLESTANI N.; KAFI M.; HOSSEINI A.; SAEB M.; SARKOOHI P. 2012. Gene expression pattern of adiponectin and adiponectin receptors in dominant and atretic follicles and oocytes screened based on brilliant cresyl blue staining. Anim Reprod Sci. 131(1-2):30-40.

TIAN, W.N.; BRAUNSTEIN, L.D.; PANG, J.; STUHLMEIER, K.M.; XI, Q.C.; TIAN, X., STANTON, R.C. 1998. Importance of glucose-6-phosphate dehydrogenase activity for cell growth. J Biol Chem 273(17):10609-17.

TIFFIN, G.J.; RIEGER,D.; BETTERIDGE, K.J.; YADAV B.R.; KING, W.A. 1991. Glucose and glutamine metabolism in pre-attachment cattle embryos in relation to sex and stage of development. J. Reprod. Fert. 93:25-32.

TWAGIRAMUNGU, H.; MORIN, N.; GUILBAULT, L.A.; SIRARD, M.A.; BOUSQUET, D. 1998. Media and time of oocytes transport influence their developmental competence for in vitro production of bovine embryos. Theriogenology, 49:299.

YONG, H. Y.; LEE, B. C.; HWANG, W. S. 1997. Effect of oocyte diameter on in vitro nuclear maturation of Korean native cattle oocyte. Theriogenology 47:205.

WONGSRIKEAO, P; OTOI , T; YAMASAKI , H; AGUNG, B; TANIGUCHI, M; NAOI, H; SHIMIZU, R; NAGAI, T. 2006.Effects of single and double exposure to brilliant cresyl blue on the selection of porcine oocytes for in vitro production of embryos. Theriogenology 66:366-372.

WU, Y.G.; LIU, Y.; ZHOU, P.; LAN, G.C.; HAN, D.; MIAO, D.Q.; TAN, J.H. 2007. Selection of oocytes for in vitro maturation by brilliant cresyl blue staining: a study using the mouse model. Cell Res. 17:722-31. 